\section{Chronic Pain and Predictive Factors in the C-Section Surgery}

\author{
Sanchez Brotons $\mathbf{M J}^{1}$, Echevarria $\mathbf{M}^{1 *}$, Turmo $\mathbf{M}^{1}$ and Almeida \\ $\mathrm{C}^{2}$
}

${ }^{1}$ Department of Anesthesiology, Valme Hospital, Seville, Spain

${ }^{2}$ Department of biostatistics, University of Seville, Seville, Spain

\begin{abstract}
Objective: To determine the occurrence of chronic pain after the surgery in mothers who gave birth via caesarean section, and the variables that could be related to this occurrence.

Methods: A prospective cohort study based on structured interviews conducted in person 24 hours after the caesarean section and over the phone at 4 months. The main variable was the presence of chronic pain from the surgical wound at 4 months. Chronic Post-Caesarean Section Pain (CPCSP) was considered to be when the Verbal Numerical Rating Scale (VNRS) was $\geq 5$. The variables prior to the chronic pain and previous caesarean section, such as pain during labour and how long it lasted, epidural anaesthesia, anaesthetic technique, nature of the caesarean section, type of incision, post-surgical pain and breastfeeding, were analysed. A univariate and multivariate analysis of logistic regression was carried out.

Results: 397 patients (98.75\%) completed the study. An $11.8 \%$ incidence of CPCSP was observed, which was significantly related with previous chronic pain $(P=0.02)$, pain during labour $(P=<0.0005)$, duration of labour $(P=0.03)$ and type of surgical incision $(P=0.006)$. In the multivariate analysis, the type of surgical incision and breastfeeding were found to have a significant influence. Conclusion: The event of the pain becoming chronic after the caesarean section surgery was verified and its relation with the pain during labour was observed. However, further research is necessary to confirm our discoveries on the beneficial effect of Pfannenstiel incision and breastfeeding.
\end{abstract}

Keywords: Anesthesia; Cesarean Section; Chronic Pain; Pain; Postoperative; Spinal

\section{Introduction}

Over the last decade, there has been a growing interest in understanding the causes and mechanisms behind the transition from

*Corresponding author: Echevarria M, Department of Anesthesiology, Valme Hospital, Avda, Bellavista, s/n 14041 Seville, Spain, Tel: +34 667406863; E-mail: mercedes.echevarria@terra.com

Citation: Brotons MJS, Echevarria M, Turmo M, Almeida C (2016) Chronic Pain and Predictive Factors in the C-Section Surgery. J Anesth Clin Care 3: 015.

Received: December 22, 2015; Accepted: March 05, 2016; Published: March 21, 2016 acute pain to chronic pain following surgical procedures. Post-surgery tissue trauma, such as that following the amputation of limbs, a thoracotomy, a mastectomy and even inguinal herniorraphy, represents a common cause of Chronic Post-Surgical Pain (CPSP) [1-4]. It is believed that this process by which acute post-surgery pain becomes chronic is mediated by a series of prognostic factors, amongst which we must highlight female sex, being less than 55 years of age, having poor control of acute pain and the person's own psychosocial factors $[2,3]$.

There is not an extensive range of publications that have analysed chronic pain following a caesarean section and, although they have indeed noted that it exists, there is much variability in the results as a consequence of the differences in the design of the study. Most of the few studies available are retrospective, including the first that looked at the issue. Through surveys sent to mothers after a period of over six months after the surgery, these studies investigated its presence and the possible predictive factors behind it [5-8], showing an incidence of around $18 \%$, with incapacitating pain that had a negative impact on a mother's activities and her relationship with her child reaching $6 \%$ [8]. In recent prospective studies, it has been estimated that this complication was shown two to three months after surgery in 9\%-15\% of cases [9-12]. When mothers were followed up until 12 months after surgery, a prevalence of $1 \%-4 \%$ was recorded $[13,14]$. According to this research, the possible predictive factors point to the anaesthetic technique used $[5,11]$, age [11], whether the surgery was urgent or planned and the type of incision [15], and the personal history of the woman, such as the presence of chronic pain $[5,7,10,11]$. Most of authors also agree that the intensity of the postoperative acute pain is a predictive factor [5,7,9-11].

At present, the amount of people who undergo a caesarean section can fluctuate between $15 \%-30 \%$, depending on the country, culture and hospitals. If we are aware that there exists the risk of pain becoming chronic after surgery, it is important to know which individual factors can lead to this happening. The aim of our study was to prospectively determine the incidence of Chronic Post-Caesarean Section Pain (CPCSP) in our health area of reference and to investigate the possible obstetric anaesthetic and maternal variables that could be related to its presence.

\section{Patients and Method}

After a retrospective study had been carried out, in which chronic pain following a caesarean section was shown to be at $18.75 \%$ in 66 mothers, a prospective cohort study was designed. This study was directed at women who had given birth via caesarean section and had the aim of assessing the presence of chronic pain following the surgery and the possible predictive factors. Its development was approved by our hospital's Ethics Committee, Valme University Hospital in Seville.

Upon arrival to the operating room, routine monitoring was performed (NIBP, ECG, $\mathrm{SpO}_{2}$ ). Spinal puncture was performed at L2-L3 using an atraumatic Sprotte-type needle. We administered 8-10 $\mathrm{mg}$ of hyperbaric $0.5 \%$ bupivacaine and 12.5 micrograms of fentanyl. In patients who received obstetric analgesia administered ropivacaine $0.75 \%$ fractionally through the epidural catheter. 
All patients, at 24 hours after caesarean when the investigator went to interview the patient, were notified of the aim of the study and had to give their informed consent in order to be included. Apart from requesting not to be included in the study, among the reasons for exclusion were women with communication difficulties due to the language or others from low socio-cultural backgrounds, as well as problems in conducting follow-up after being discharged from hospital.

The research was based on structured interviews conducted in person 24 hours after the caesarean section, and over the phone after four months. The main variable was the presence of chronic pain in the area of the surgical wound after four months. CPCSP was defined as when pain was equal to or greater than 5 (where 0 was no pain at all and 10 the maximum level of pain) on the Verbal Numerical Rating Scale (VNRS). Possible predictive factors that were included were variables related to personal history, both the anaesthetic and obstetric peripartum period and the postoperative period.

24 hours after the caesarean section, an anaesthesiologist visited the patients, at which time they were invited to participate in the study. They were asked about the presence of pain at rest, which was measured using the VNRS, from 0-10. In this interview, both personal history details and variables related to the childbirth and intervention period were recorded.

Four months after the surgery, the mothers were contacted via telephone and a structured interview was carried out, which followed the model shown in appendix 1. This entailed research into the presence of pain and its nature, the degree to which it made the realisation of daily activity difficult and the presence of psychological symptoms such as depression, anxiety and fibromyalgia, which appear after the caesarean section. Moreover, it was checked whether or not the newborn was breastfed. The telephone interview was always carried out by the same researcher.

Amongst the personal details that were asked were chronic pain history and information on any previous caesarean sections. The variables related to the birth were the time in labour, pain during labour and whether they had epidural anaesthesia. In relation to the intervention, the nature of the caesarean, the type of surgical incision and the anaesthetic technique (general or local-regional anaesthesia) were considered.

\section{Statistical study}

Following initial refinement of the data, these were described with averages and standard deviations for quantitative variables or median and $\mathrm{P}_{25}$ and $\mathrm{P}_{75}$ percentiles in the case of asymmetrical distributions, and with percentages for qualitative variables. This summary was realised according to the CPCSP being studied. In order to identify qualitative variables related to $5 \%$ CPCSP, univariate analysis was carried out before each one, with the response given via the Chi-square test, or the non-asymptotic approaches of the Monte Carlo method and the exact test. In order to see if there were differences in the average levels of quantitative variables between the two CPCSP groups, the Student's t-test was applied to independent samples and the Mann-Whitney $U$ test in the case of abnormal distributions. Subsequently, those variables with a statistical significance of $<25 \%$ in the univariate analysis were introduced into the multivariate model for the final selection. Statistical analysis of the data was performed using the IBM SPSS 22.0 software for Windows. Values of P $\leq 0.05$ were considered to be statistically significant.

\section{Sample size}

In order to identify predicting factors of CPCSP (yes/no), we tried to generate a multivariate model of binary logistical regression. The sample size was determined using the Freeman $10 \mathrm{x}(\mathrm{k}+1)$ equation, whereby $\mathrm{k}$ is the number of potential predicting factors considered (VNRS during labour, breastfeeding and type of surgical incision), making it necessary to study a minimum of 80 patients, 40 with CPCSP and another 40 without it.

\section{Results}

Over 18 months, 402 patients were included in the study. The age of pregnant women was $32.2 \pm 5.2$, the weight $76 \pm 14 \mathrm{~kg}$ and height

\begin{tabular}{|c|c|c|c|c|}
\hline & $\begin{array}{c}\text { Total } \\
\text { patients }\end{array}$ & No CPCSP & CPCSP & $P$ \\
\hline & $n=402$ & $n=350$ & $n=47$ & \\
\hline Age & $32.2 \pm 5.2$ & $32.43 \pm 5.2$ & $31.17 \pm 4.7$ & 0.17 \\
\hline Chronic pain history & & & $0(0)$ & \multirow{3}{*}{0.02} \\
\hline Yes & $47(11.7)$ & $42(100)$ & $47(13.23)$ & \\
\hline No & $355(88.3)$ & $308(86.76)$ & & \\
\hline \multicolumn{4}{|l|}{ First caesarean section } & \multirow{3}{*}{0.68} \\
\hline Yes & $271(67.4)$ & $236(90.76)$ & $30(9.23)$ & \\
\hline No & $131(32.6)$ & $114(87.02)$ & $17(12.97)$ & \\
\hline Labour & & $213(87.65)$ & $30(12.34)$ & \multirow{3}{*}{0.69} \\
\hline Yes & $243(61.29)$ & $137(88.96)$ & $17(11.03)$ & \\
\hline No & $154(38.71)$ & & & \\
\hline Duration of labour & $259(44.4)$ & $235(90.73)$ & $24(9.26)$ & \multirow{3}{*}{0.03} \\
\hline$<4$ hours & $138(56.6)$ & $115(83.33)$ & $23(16.7)$ & \\
\hline$>4$ hours & & & & \\
\hline \multicolumn{4}{|l|}{ Epidural analgesia } & \multirow{3}{*}{0.3} \\
\hline Yes & $187(47.1)$ & $162(86.63)$ & $25(13.36)$ & \\
\hline No & $210(52.89)$ & $188(94)$ & $22(6)$ & \\
\hline \multicolumn{4}{|l|}{$\begin{array}{l}\text { Nature of the caesarean } \\
\text { section }\end{array}$} & \multirow{4}{*}{0.1} \\
\hline Scheduled & $133(33.1)$ & $122(91.72)$ & $11(8.27)$ & \\
\hline Urgent & $256(63.7)$ & $217(86.45)$ & $34(13.54)$ & \\
\hline Emergency & $13(3.2)$ & $11(84.61)$ & $2(15.38)$ & \\
\hline Anaesthetic technique & $211(52.5)$ & $180(87.37)$ & $26(12.62)$ & \multirow{4}{*}{0.06} \\
\hline Intradural & $167(41.5)$ & $\begin{array}{c}146 \\
(87.412)\end{array}$ & $21(12.57)$ & \\
\hline Epidural & $24(6)$ & $24(100)$ & & \\
\hline \multicolumn{4}{|l|}{ General } & \\
\hline Incision & & & & \multirow{3}{*}{0.006} \\
\hline Pfannenstiel & $353(87.8)$ & $317(89.04)$ & 35 (10.95) & \\
\hline Infraumbilical & $49(12.2)$ & $37(75.51)$ & $12(24.48)$ & \\
\hline Any positive sign of & $170(42.3)$ & 124 & $46(97.9)$ & \multirow{4}{*}{0.0005} \\
\hline Anxiety & $44(25.9)$ & $40(32.3)$ & $4(8.4)$ & \\
\hline Depression & $100(58.8)$ & $69(55.6)$ & $31(67.4)$ & \\
\hline Fibromyalgia & $26(15.3)$ & $15(12.1)$ & $11(23.9)$ & \\
\hline \multicolumn{4}{|l|}{ Breastfeeding } & \multirow{3}{*}{0.6} \\
\hline Yes & $197(49.6)$ & $180(91.7)$ & $17(9)$. & \\
\hline No & $200(49.8)$ & $170(85)$ & 30 (15) & \\
\hline
\end{tabular}

Table 1: Characteristics of all patients, distributed according to whether or not CPSCP was present data expressed as the number of mothers, percentage. Average age and SD Total number of patients with a psychological illness. From this total, the percentage is given of those that showed signs of anxiety/ depression/fibromyalgia. 
$160 \pm 6.5 \mathrm{~cm}$. It was not possible to perform the follow-up check after four months in the case of five patients (98.75\%). $11.8 \%$ reported some kind of previous chronic pain, with the most frequent being lower back pain in $42.9 \%$ of cases, followed by migraines in $23.8 \%$. The average pain intensity described by the patients according to the VNRS was $7.5 \pm 1.4\left(\mathrm{P}_{25} 6-\mathrm{P}_{75} 8\right) .83 .3 \%$ regularly took some kind of analgesic (Table 1).

$67.4 \%$ of mothers did not have any history of a previous caesarean section. In $33.1 \%$ of cases the surgery was planned, in $63.7 \%$ it was urgent and $3.2 \%$ were an emergency. In $87.8 \%$ of cases, there was a Pfannenstiel incision, whilst in $12.2 \%$ it was supra-umbilical midline. With regard to the anaesthetic technique used, $52.5 \%$ of the caesareans were performed under spinal anaesthetic, $41.5 \%$ with epidural anaesthetic, and only $6 \%$ with general anaesthetic (Table 1 ). Twins were born in $1.5 \%$ of the cases.

Of the women who went into labour, $73.9 \%$ received epidural anaesthesia. In $55.6 \%$ of the patients, the labour time was over four hours before the indication that a caesarean section was needed (Table 1).

In the individual postoperative interview, $49 \%$ reported pain only in the area of the surgical incision, $46.3 \%$ also had pain in the area surrounding it and in $4.7 \%$ of cases the pain was referred even further afield (Table 2). $97.8 \%$ of patients received intravenous analgesia (1gr metamizol magnesico) and 2.2\%, epidural. The intensity of the pain after 24 hours and the pain during labour are shown in table 3.

\begin{tabular}{|c|c|c|c|c|}
\hline & Total patients & No CPCSP & CPCSP \\
\hline & & $n=402$ & $n=350$ & $n=47$ \\
\hline \multirow{3}{*}{ Location } & Wound & $197(49)$ & $172(49.1)$ & $25(53.2)$ \\
\hline & $\begin{array}{l}\text { Wound and surrounding } \\
\text { area }\end{array}$ & $186(46.3)$ & $165(47.2)$ & $16(34)$ \\
\hline & Further afield & $19(4.7)^{\star}$ & $13(3.7)$ & $6(12.8)$ \\
\hline
\end{tabular}

Table 2: Localisation of pain 24 hours after the operation.

${ }^{*} P=0.01$. Differences between pain in the wound and the area surrounding it, and that spread to further afield.

\begin{tabular}{|c|c|c|c|c|c|c|}
\hline & & \multirow{2}{*}{$\begin{array}{c}\text { Average } \\
\text { standard } \\
\text { deviation } \\
\text { (min.-max.) }\end{array}$} & \multirow{2}{*}{$\begin{array}{l}\text { Median } \\
\left(\mathbf{P}_{25}-\mathbf{P}_{75}\right)\end{array}$} & \multirow[b]{2}{*}{$P<.05$} & \multicolumn{2}{|c|}{ Cl 95\% } \\
\hline & & & & & Lower & Upper \\
\hline \multirow{2}{*}{$\begin{array}{l}\text { Pain during } \\
\text { labour on } \\
\text { VNRS }\end{array}$} & $\begin{array}{c}\text { No } \\
\text { CPCSP }\end{array}$ & $\begin{array}{c}4.27 \pm 2.95 \\
(0-10)\end{array}$ & $5(1-7)$ & \multirow{2}{*}{0.0001} & \multirow{2}{*}{-4} & \multirow{2}{*}{-1} \\
\hline & CPCSP & $\begin{array}{c}6.66 \pm 1.96 \\
(0-10)\end{array}$ & $7(7-7)$ & & & \\
\hline \multirow{2}{*}{$\begin{array}{c}\text { Pain } 24 \\
\text { hours after } \\
\text { on VNRS }\end{array}$} & $\begin{array}{c}\text { No } \\
\text { CPCSP }\end{array}$ & $\begin{array}{c}5.87 \pm 1.79 \\
(1-10)\end{array}$ & $6(5-7)$ & \multirow{2}{*}{0.9} & \multirow{2}{*}{-1} & \multirow{2}{*}{1} \\
\hline & CPCSP & $\begin{array}{c}5.96 \pm 1.54 \\
(3-10)\end{array}$ & $6(5-7)$ & & & \\
\hline
\end{tabular}

Table 3: Pain intensity during labour and 24 hours after the caesarean.

During the telephone interview, pain after two months was observed in $41.56 \%$ of cases and after four months in $39.3 \%$, of which only 47 women, $11.8 \%$, described a VNRS of $\geq 5$ (criteria for CPSCP). $26.3 \%$ of patients reported that the pain appeared three months after the caesarean section. In $68.4 \%$ of cases, the pain did not interfere with daily activities, whilst in $5.3 \%$ it was fairly limiting. The intensity of the pain and its nature, distributed according to CPCSP criteria, are shown in table 4 and 5 , respectively. The characteristics of the surgical incision are shown in table 6.

\begin{tabular}{|c|c|c|c|}
\hline VNRS after $\mathbf{4}$ months & Medium & Minimum-maximum & Median $\mathbf{P}_{\mathbf{2 5}}-\mathbf{P}_{\mathbf{5 0}}$ \\
\hline No CPCSP $(\mathrm{n}=350)$ & $1.05 \pm 1.61$ & 0.4 & $0(0-3)$ \\
\hline $\operatorname{CPCSP}(\mathrm{n}=47)$ & $5.89 \pm 0.81$ & 5.8 & $6(5-6)$ \\
\hline
\end{tabular}

Table 4: Description of the pain intensity after 4 months.

\begin{tabular}{|c|c|c|}
\hline \multirow{2}{*}{ Location } & No CPCSP & CPCSP \\
\cline { 2 - 3 } & VNRS $<5$ & VNRS $\geq 5$ \\
\cline { 2 - 3 } & $\mathrm{n}=118$ & $\mathrm{n}=47$ \\
\hline Wound/Wound and surroundings/Further afield & $85 / 24 / 9$ & $38 / 9 / 0$ \\
\hline Irradiated Yes/No & & \\
\hline Continuous/Intermittent & $93 / 24$ & Mar-44 \\
\hline When touched/Cold & $9 / 109$ & Dec-35 \\
\hline Deep/Superficial & $100 / 18$ & $41 / 6$ \\
\hline Burning/Electrical current/Needle prick & $15 / 103$ & $13 / 34$ \\
\hline Menstruation Yes/No & $74 / 24 / 20$ & $34 / 8 / 5$ \\
\hline Increased with menstruation Yes/No ( $=66$ and 33) & $66 / 52$ & $33 / 14$ \\
\hline
\end{tabular}

Table 5: Nature of pain 4 months after the operation, in patients who reported some degree of pain.

Data expressed as the number of patients.

\begin{tabular}{|c|c|c|c|}
\hline & Patients who completed the study & No CPCSP & CPCSP \\
\cline { 2 - 4 } & $\mathrm{n}=397$ & $\mathrm{n}=350$ & $\mathrm{n}=47$ \\
\hline$<5 \mathrm{~cm}$ & $3(0.8)$ & $3(0.9)$ & 0 \\
\hline $5-10 \mathrm{~cm}$ & $264(66.5)$ & $232(66.3)$ & $32(31.9)$ \\
\hline $11-15 \mathrm{~cm}$ & $130(32.7)$ & $115(32.9)$ & $15(68.1)$ \\
\hline
\end{tabular}

Table 6: Nature of the surgical incision.

In $42.3 \%$ of the women who completed the study, some psychological symptoms during the post-caesarean period were registered (Table 1). $49.6 \%$ of the mothers were breastfeeding their baby. Figure 1 displays the flow diagram of the total births attended in the 18 months of the study, the women included and those who completed the study, as well as their obstetric and anaesthetic particularities.

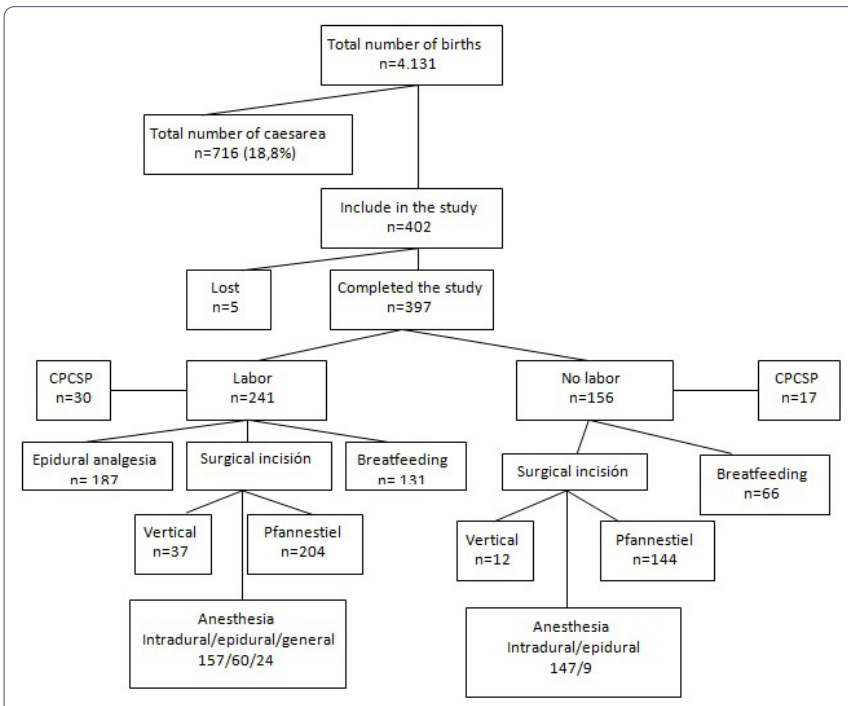

Figure 1: Flow diagram describing the sample of women included in the 18-month study and obstetric and anesthetic properties.

In order to identify the variables related to CPCSP, a univariate analysis was carried out that significantly related $(\mathrm{P}<0.05) \mathrm{CPCSP}$ and 
previous chronic pain $(\mathrm{P}=0.02)$, pain during labour $(\mathrm{P}=<0.0005)$, duration of labour $(\mathrm{p}=0.03)$, the type of surgical incision $(\mathrm{P}=0.006)$ and the presence of psychological symptoms during the post-caesarean period $(\mathrm{P}<0.0005)$ (Table 1$)$.

There was later an attempt to conduct multivariate analysis in order to identify variables independently related to CPCSP, with the model not turning out to be stable. Despite this, the significant influence of the surgical incision and breastfeeding variables was observed (Table 7).

\begin{tabular}{|c|c|c|c|c|}
\hline & \multirow[b]{2}{*}{$\mathrm{P}$} & \multirow{2}{*}{ OR } & \multicolumn{2}{|c|}{ Cl 95\% } \\
\hline & & & Lower & Higher \\
\hline Duration of labour VNRS & 0.001 & 0.8 & 1.07 & 1.29 \\
\hline Breastfeeding & 0.05 & 2.8 & 0.175 & 0.739 \\
\hline Pfannenstiel incision & 0.02 & 3.7 & 0.119 & 0.632 \\
\hline
\end{tabular}

\section{Discussion}

Our results highlight that four months after surgery, pain was present in $11.8 \%$ of women that had undergone a caesarean section, and the type of surgical incision and breastfeeding were identified as possible protective factors of CPCSP.

The first publication on the presence of chronic pain following a surgical procedure was carried out by Crombie et al., in 1998 [16]. One of the problems with these studies is the diversity of criteria for the definition of postoperative chronic pain, and the time that must pass has been much debated, although the exact duration of the inflammatory process is still yet to be determined. Although PCSP is defined as pain that lasts more than two months after a surgical procedure, excluding other possible causes of pain [2], some experts suggest that this period must be at least 3-6 months after surgery [17]

In 2004, Nikolajsen et al., studied the presence of chronic pain after a caesarean section for the first time [5], and since then different authors have done research in this area and confirmed its occurrence. These authors included 244 patients over the course of a year. The study was based on a questionnaire sent to mothers between 6-17.6 months after the surgery. They were asked about the duration and intensity of any postoperative pain that they had around their abdominal scar and, if the pain was still present at the time of responding to the questionnaire, to describe the frequency, intensity and impact it was having on their daily life. $90.2 \%$ of the women answered the questionnaire, with the results showing that $18.6 \%$ suffered from pain three months after the operation, and $12.3 \%$ still had the pain even after ten months. The intensity of the pain in the immediate postoperative phase was found to be linked to its becoming chronic.

Nardi et al., published the results of their research, which analysed the presence of CPCSP using surveys that they had sent to 220 mothers a minimum of six months after the surgery [11]. They also asked about the presence of pain, its intensity, and the effects this was having on their daily life, and retrospectively included possible risk factors taken from the patients' clinical history. The percentage of answers that they obtained was $76 \%$, and the average return time of the survey was ten months (range 8-12). The incidence of CPCSP was $15 \%$, and $4 \%$ reported a deterioration in their quality of life due to moderate to severe pain. They highlighted risk factors as being a history of previous chronic pain (migraines and lower back pain), being younger, having had the operation under general anaesthesia and the presence of pain in the postoperative period.

Most of the literature shows that CPCSP has an incidence of $9 \%-18 \%$ in women who have had a caesarean section. These results come from retrospective studies based on surveys sent more than six months after the operation $[5,7,11,15]$. It is evident that there are various problems with bias in this methodology, such as a rate of response that was lower than the telephone call (bias of no response), the difficulties for people from low socio-cultural backgrounds, and the bias caused by loss of memory in an interview taking place after the event. Obtaining results via a telephone interview has advantages such as the high response rate that one can get, as well as its versatility for all kinds of questionnaire and specific questions within them, as long as they are conducted by a trained and responsible interviewer. The main possible source of bias is the various interpretations that the interviewer could make or the inadvertent suggestion of expected responses.

Sng et al., conducted research via telephone calls and, prospectively, the incidence of CPCSP three months after surgery in 857 Asian women, and they included analysis of peri-operative, obstetric and surgical factors that could be predictors of CPCSP. The authors observed that $9.2 \%$ of the mothers suffered from CPCSP, $9.8 \%$ reported constant pain, and a further $9.8 \%$ said it was daily. The predictive factors that they observed were postoperative pain (OR 1.38) and the presence of pain in areas other than that of the surgical incision (OR 2.47) [10].

There are prospective studies in which follow-up checks have been carried out up to 12 months after the caesarean, and they observed a prevalence of $1-4 \%$ per year $[13,14]$. However, the authors excluded from the follow-up those women who did not mention any pain during the interview. If we consider that $26.3 \%$ of women in our study reported the start of pain at three months, which was probably related to the start of the menstrual period, these authors could exclude patients that suffered from pain after the interviews.

The disparity in the published results could be caused by the differences in the investigations' design and the definition of the pain variable [18]. There are currently arguments that suggest that the origin of this chronic pain is neuropathic, both due to its nature and intensity [19]. However, it is of interest to point out that six months after the operation, different authors noted that in over $85 \%$ of mothers who undergo a caesarean section and experience pain, the average intensity on the VNRS was less than $2[7,13,18,20]$, when in literature, chronic neuropathic pain is associated with a higher intensity (VAS of 7-8/10) [21]. It should be noted that the mothers were informed of the aim of the study, that the follow-up was carried out 24 hours and then four months after the operation, and that pain with a degree of intensity equal to or over 5 on the VNRS and localised or related to the surgical area was valued as CPCSP. Moreover, the kind of pain and its nature were analysed using neuropathic pain descriptors.

With regard to the predictive factors that we investigated, in the same way as Liu et al., in their prospective study, we did not observe any differences with the anaesthetic technique, nature of the surgery or previous history of having had a caesarean section [14]. Nor did we find any relationship between the pain intensity at 24 hours and CPCSP, with this result being similar to that observed by Liu et al., [14], and in contrast to most of the authors. However, it has been reported that $15 \mathrm{mg}$ of hyperbaric bupivacaine associated with 100 
micrograms of morphine hydrochloride reduced the incidence of DCP to $2.2 \%$ compared to the administration of lower doses of hyperbaric bupivacaine [12]. However, the pain intensity during labour, prior to the caesarean, was indeed found to be related to CPCSP. This aspect had not previously been investigated, as the length of labour, variables which are may be linked to each other.

In the area of obstetrics, the type of surgical incision and the presence of CPCSP have been little investigated. Via the sending of a questionnaire, Loos et al., analysed the incidence of persistent pain in 690 mothers who had undergone a Pfannenstiel incision for caesarean surgery (93\%) or a hysterectomy (7\%). Up to $33 \%$ of the mothers experienced PCSP in the incision even two years after surgery, with $9 \%$ suffering from moderate to severe pain [15]. In this study, only patients subject to a Pfannenstiel incision were considered, in contrast to our work, which included analysis of two types of surgical incisions, observing that infraumbilical incision may be a predictive factor of chronic pain. The studies must also consider the length of surgical incisions, which can affect different amounts of nerves from the lower abdominal wall, although we did not observe that a larger incision would favour the presence of CPCSP.

We have found it surprising that past history of chronic pain has been found to relate to CPCSP in a way contrary to that expected, against that which the existing literature suggests. The possible explanation for this could be the definition of CPCSP, which does not include the mothers with a VNRS of equal to or less than 4 and just assesses the pain in the area of the surgical incision, with this even having been linked to the presence of other types of pain such as in the lower back or pelvis, or migraines $[5,7,10,11,19]$. This is in contrast to other studies that also include lower pain intensities in their analysis. However, and in the area of literature, the presence of anxiety, depression or fibromyalgia following the surgery was significantly related to CPCSP, with this occurring in $97.9 \%$ of patients in this group [9]. We do not know if these circumstances are related to, and condition, each other.

The possible effects that breastfeeding could have on the appearance or not of CPCSP had not been investigated up until now. We include this variable in our study and have observed that it is a protective factor in the development of CPCSP. This beneficial effect of breastfeeding could be as a consequence of the release of beta endorphins, which has been observed during this process [22,23], and the analgesic effect that they have in procedures such as the insertion of intrauterine devices [24]. Moreover, the suction of the nipple causes an increase in the secretion of prolactin and oxytocin, which induce a state of less anxiety. Neuropeptide oxytocin contributes to the regulation of different physiological functions, including nociception [25], and can have a protective effect, via inhibitory activity that modulates the transmission of pain at a spinal level, or even at a supra-spinal level, thus regulating negative emotions [26,27].

We consider several limitations in the study. The first is related to chronic pain history or psychological symptoms that the patient reported and that were not corroborated either by clinical history or confirmation after a deliberate search on our part, leading to probable subjectivity. Other limitations include the result of the multivariate analysis, which cannot be conclusive and should be corroborated with the results of a study that includes a greater number of CPCSP events. Despite this, in the univariate analysis, we clearly identify the resulting variables that match that clinically expected.
With the constant increase in caesarean section births, the evidence that acute pain can become chronic after surgery and the fact that this is related to factors linked to the obstetric anaesthetic process, the role of the anaesthetist in the search for better mid-term results, rather than just those in the short-term, would seem key. In the preoperative phase, it is necessary to identify any pregnant women with a high risk of experiencing CPCSP and individualise peripartum management, carrying out measures that may allow such factors, and thus the presence of chronic pain, to be controlled. It is also necessary to conduct further investigations on the beneficial effects of a Pfannenstiel incision and breastfeeding, in order to confirm our findings.

\section{References}

1. Perkins FM, Kehlet $\mathrm{H}$ (2000) Chronic pain as an outcome of surgery. A review of predictive factors. Anesthesiology 93: 1123-1133.

2. Macrae WA (2001) Chronic pain after surgery. Br J Anaesth 87: 88-98.

3. Macrae WA (2008) Chronic post-surgical pain: 10 years on. $\mathrm{Br} \mathrm{J}$ Anaesth 101: $77-86$.

4. Kehlet H, Jensen TS, Woolf CJ (2006) Persistent postsurgical pain: risk factors and prevention. Lancet 367: 1618-1625.

5. Nikolajsen L, Sørensen HC, Jensen TS, Kehlet H (2004) Chronic pain following Caesarean section. Acta Anaesthesiol Scand 48: 111-116.

6. Declercq E, Cunningham DK, Johnson C, Sakala C (2008) Mothers' reports of postpartum pain associated with vaginal and cesarean deliveries: results of a national survey. Birth 35: 16-24.

7. Kainu JP, Sarvela J, Tiippana E, Halmesmäki E, Korttila KT (2010) Persistent pain after caesarean section and vaginal birth: a cohort study. Int J Obstet Anesth 19: 4-9.

8. Vermelis JM, Wassen MM, Fiddelers AA, Nijhuis JG, Marcus MA (2010) Prevalence and predictors of chronic pain after labor and delivery. Curr Opin Anaesthesiol 23: 295-299.

9. Eisenach JC, Pan PH, Smiley R, Lavand'homme P, Landau R, et al. (2008) Severity of acute pain after childbirth, but not type of delivery, predicts persistent pain and postpartum depression. Pain 140: 87-94.

10. Sng BL, Sia AT, Quek K, Woo D, Lim Y (2009) Incidence and risk factors for chronic pain after caesarean section under spinal anaesthesia. Anaesth Intensive Care 37: 748-752.

11. Nardi N, Campillo-Gimenez B, Pong S, Branchu P, Ecoffey C, et al. (2013) [Chronic pain after cesarean: Impact and risk factors associated]. Ann $\mathrm{Fr}$ Anesth Reanim 32: 772-778.

12. de Brito Cançado TO, Omais M, Ashmawi HA, Torres ML (2012) Chronic Pain after Cesarean Section. Influence of Anesthetic/Surgical Technique and Postoperative Analgesia. Rev Bras Anestesiol 62: 762-774.

13. Eisenach JC, Pan P, Smiley RM, Lavand'homme P, Landau R, et al. (2013) Resolution of pain after childbirth. Anesthesiology 118: 143-151.

14. Liu TT, Raju A, Boesel T, Cyna AM, Tan SG (2013) Chronic pain after caesarean delivery: an Australian cohort. Anaesth Intensive Care 41: 496-500.

15. Loos MJ, Scheltinga MR, Mulders LG, Roumen RM (2008) The Pfannenstiel incision as a source of chronic pain. Obstet Gynecol 111: 839-846.

16. Crombie IK, Davies HT, Macrae WA (1998) Cut and thrust: antecedent surgery and trauma among patients attending a chronic pain clinic. Pain 76 : 167-171.

17. Pogatzki-Zahn EM, Englbrecht JS, Schug SA (2009) Acute pain management in patients with fibromyalgia and other diffuse chronic pain syndromes. Curr Opin Anaesthesiol 22: 627-633. 
18. Lavand'homme P (2013) Chronic pain after childbirth. Curr Opin Anaesthesiol 26: $273-277$

19. Johansen A, Romundstad L, Nielsen CS, Schirmer H, Stubhaug A (2012) Persistent postsurgical pain in a general population: prevalence and predictors in the Tromsø study. Pain 153: 1390-1396.

20. Bollag L, Richebe P, Siaulys M, Ortner CM, Gofeld M, et al. (2012) Effect of transversus abdominis plane block with and without clonidine on post-cesarean delivery wound hyperalgesia and pain. Reg Anesth Pain Med 37: 508-514.

21. Torrance N, Smith BH, Bennett MI, Lee AJ (2006) The epidemiology of chronic pain of predominantly neuropathic origin. Results from a general population survey. J Pain 7: 281-289.

22. Franceschini R, Venturini PL, Cataldi A, Barreca T, Ragni N, et al. (1989) Plasma beta-endorphin concentrations during suckling in lactating women. Br J Obstet Gynaecol 96: 711-713.
23. Bodnar RJ (2013) Endogenous opiates and behavior: 2012. Peptides 50: 5595.

24. Chi IC, Wilkens LR, Champion CB, Machemer RE, Rivera R (1989) Insertional pain and other IUD insertion-related rare events for breastfeeding and non-breastfeeding women--a decade's experience in developing countries. Adv Contracept 5: 101-119.

25. Russo R, D'Agostino G, Mattace Raso G, Avagliano C, Cristiano C, et al. (2012) Central administration of oxytocin reduces hyperalgesia in mice: implication for cannabinoid and opioid systems. Peptides 38: 81-88.

26. Gutierrez S, Liu B, Hayashida K, Houle TT, Eisenach JC (2013) Reversal of peripheral nerve injury-induced hypersensitivity in the postpartum period: role of spinal oxytocin. Anesthesiology 118: 152-159.

27. Yang J, Liang JY, Li P, Pan YJ, Qiu PY, et al. (2011) Oxytocin in the periaqueductal gray participates in pain modulation in the rat by influencing endogenous opiate peptides. Peptides 32: 1255-1261.
1. Are you currently experiencing pain?
2. Have you been experiencing pain for at least two months?
3. Where is it located?
4. Is it spread to other areas?
5. What is the nature of the pain?

6. VNRS of the current pain

7. When did the pain appear?

8. What is the length of the scar?

9. Does it hurt with menstruation?

10.Do you take painkillers for the pain?

11.Do you have any signs of depression, anxiety or fibromyalgia?

12.To what degree does it make the realisation of daily activities difficult?

\section{YES NO}

YES NO

a. Wound, wound and surrounding area or further afield YES NO

a. Needle prick, burning, electrical current

b. Deep or superficial

c. Continuous or intermittent

a. Constant since the caesarean section
b. After one month
c. After three months
$<5 \mathrm{~cm} / 5-10 \mathrm{~cm} / 11-15 \mathrm{~cm}$
YES NO
YES NO
YES NO
a. Not at all
b. Not particularly
c. Quite a bit
d. A lot
YES NO

YES

Appendix 1: Telephone survey at four months. 